\title{
Modelling Predictors of Weight Gain of Children Under-Five
}

\author{
Hussein Salifu ${ }^{1}$, Nyemekye Gabriel ${ }^{2}$, Isaac Zingure ${ }^{3}$ \\ ${ }^{1}$ Ghana Senior High School, Department of Mathematics, Tamale, Ghana \\ ${ }^{2}$ Tamale Technical University, School of Applied Sciences, Department of Statistical Science, Tamale, Ghana \\ ${ }^{3}$ Jema Senior High School, Department of Mathematics, Jema, Ghana
}

\section{Email address:}

husseinstia@gmail.com (H. Salifu),ngabriel@tatu.edu.gh (N. Gabriel), zingure11@yahoo.com (I. Zingure)

\section{To cite this article:}

Hussein Salifu, Nyemekye Gabriel, Isaac Zingure. Modelling Predictors of Weight Gain of Children Under-Five. American Journal of Theoretical and Applied Statistics. Vol. 10, No. 2, 2021, pp. 99-110. doi: 10.11648/j.ajtas.20211002.12

Received: February 15, 2021; Accepted: March 1, 2021; Published: March 17, 2021

\begin{abstract}
This study examined the determinants of weight gain by children less than five years in the Kintampo municipality of the Bono East Region of Ghana using multivariate analysis of variance (MANOVA) procedure and profile analysis. The study revealed that the minimum weight gain at the first month for males and females are $1.8 \mathrm{~kg}$ and $1.6 \mathrm{~kg}$ respectively and that mean weights gain by children under five years was not the same across feeding type. Profile plots of main effect revealed that baby's age group 0-6, Exclusive Breast Feeding (EBF), parity levels 6, 7 and mothers who were formally employed are associated with lower mean effects since they fall below the average mean weight. However, child age group 13-18, breast milk substitute and parity 7 are above the average mean weight line of 7.5, indicating significant effect. Interaction plots indicated that the relationship between parity, mother's age group, employment type and weight depend on other predictor variables. Parity depends on mother's age but mother's age does not depend on the child age group with respect to weight gain. Also, employment type neither depend on religion nor child age group but it depends on educational level with respect to weight gain. The MANOVA results showed that feeding type, parity and child age are the influential factors in determining the weight gain of children less than five years. Further, the study revealed that there exists some relationship between feeding type and mother's education, parity and mother's age group and between occupation and mother's age group with respect to weight gain confirming the profile results. It is therefore recommended that nursing mothers should be encouraged to feed their children themselves since feeding practice has a great influence in the growth of the child at the infant stage.
\end{abstract}

Keywords: MANOVA, Feeding Type, Weight Gain, Interaction, Profile Plot

\section{Introduction}

A number of researches have been carried out on weight for age in babies using different methodologies. According to United Nations International Children and Education Fund [1], globally, one out of seven infants is born with low birth weight. The incidence has not declined in the last decade in Sub-Saharan Africa (SSA) and Asia. It has also been estimated that the prevalence of low-birth-weight babies in Ghana is $13.0 \%$. Maternal age $(<20$ years and $>35$ years $)$, stress during pregnancy, maternal under nutrition before pregnancy and first parity may lead to low birth weight [2]. Other evidence adduced by considering factors related to birth weight, they may be classified as demographical, physical, psychosocial, nutritional, behavioral, previous obstetric history, morbidity during pregnancy and antenatal care. Demographic factors pertain to the age, religion, place of residence, socio-economic status (income, education and occupation).

The physical factors include the maternal height, prepregnancy weight, paternal height and weight. Nutritional factors consist of food intake as well as weight gain during pregnancy. Psychosocial factors comprise of the psychological make-up of the mother during pregnancy as well as the social factors having an effect on the mother. Health behaviors affecting birth weight include smoking as well as passive smoking and physical activity. Previous obstetric history encompasses the details of previous pregnancies as well as any previous adverse outcomes. Maternal morbidity during pregnancy checks for general morbidity or any episodic illness during pregnancy and any significant complication during pregnancy. Antenatal care 
focuses on the month of initiation as well as the number of visits and quality of the care.

Maternal age is considered to be a very important aspect in the area of birth weight studies. Leppert et al [3] in a study conducted among adolescents and older mothers in New York reported maternal age as a significant predictor of birth weight. Also, a study by Abel, Kruger and Burd [4] discovered a U-shaped relationship between age and low birth weight. Considering the effect of religion on birth weight, Dhall and Bagga [5] revealed a significant effect of religion on birth weight among babies born in North India.

Socio-Economic status (SES) mainly comprises of factors relating to education, occupation and income. Parker and Schoendorf [6], found that maternal and paternal education levels were the best overall predictors of reproductive outcomes like birth weight. Low SES was seen to be significantly related to low birth weight in a study by Deshmukh et al. [7], conducted in an urban area in India. However, a study in Thailand by Tuntiseranee et al. [8] observed that among the SES indicators, only family income correlated with birth weight.

Langhoff et al. [9] studied the relation between hereditary factors with birth weight and concluded that maternal and paternal birth weights were poor predictors of infant birth weight. Also, in a study from India conducted by Mavalankar et al. [10] showed that attributable risk for low birth weight contributed by low maternal weight was much more than that by low maternal height.

Studies have shown that rapid weight gain in infancy is essentially correlated to an increased risk of obesity during childhood and in later life [11, 12], and where as children showing poor weight gain is a sign of malnutrition [13]. Malnutrition has over the years and still remains a major public health problem. An estimated figure of about $45 \%$ of under five years children mortality are linked to malnutrition [14]. Early detection of risk factors for constant unnecessary weight gain is essential, as there is evidence that prevention and treatment of obesity at early stage of life prove to be most efficient $[15,16]$.

Examining of factors associated with weight gain, especially the relationship between child feeding practice and weight gain as it is one of the few possibly adjustable risk of malnutrition or childhood obesity is key in policy formulation. The study therefore seeks to establish the relationship between monthly mean weight gain and some maternal and child level factors. Further, it is also aimed at examining the differences between level means for one or more factors.

\section{Materials and Methods}

\subsection{Source of Data and Variables}

Data for this study was derived from a retrospective monthly repeated measurement of 145 under five-year children recorded over the period of seven months, out of which 115 observations has all required variables for the study. Variables considered in the study includes sex, baby's age, mother's age, educational level, parity, religion, occupation, marital status and feeding type and a repeated measurement of individual infant weight was recorded at seven specific time points (monthly); weight1, weight2, weight $3, \ldots$, weightt 7 .

\subsection{Multivariate Analysis of Variance (MANOVA)}

MANOVA involves analysis of several population means. This technique provides a multivariate test to compare the mean vectors of $\mathrm{k}$ random samples for significant differences when the levels of the grouping variables are two or more. MANOVA is used to investigate whether the populations mean vectors are the same and, if not, which mean components differ significantly. Consider $\mathrm{k}$ independent random samples of size $\mathrm{n}$ obtained from $p$ - variate normal populations. The model for each observation is;

$$
X_{i j}=\mu+\mu_{i}+\varepsilon_{i j}, j=1,, 2, \ldots, n, \text { and } i=1,2, \ldots, g .
$$

Where $\varepsilon_{i j}$ are independent $N_{p}(0, \Sigma)$ variables while the vector $\mu$ is an overall mean and $\tau_{i}$ represent the $i^{\text {th }}$ treatment effect with $\sum_{i=1}^{g} n_{i} \tau_{i}=0$. The components of $X_{i j}$ is a sample of $N_{p}(0, \Sigma)$ populations and that the random samples are independent. Each observation vector $X_{i j}$ in model (1) can be decomposed into components of treatment and residuals effects as;

$$
X_{i j}=\bar{x}+\left(\overline{\overline{x_{l}}}-\overline{\bar{x}}\right)+\left(x_{i j}-\overline{\overline{x_{l \jmath}}}\right)
$$

Johnson and Wichern [17].

\subsection{Model Accuracy}

1. Normal distribution: The Kolmogorov - Smirnov and Shapiro - Wilk's tests were used to test the assumption that the dependent variables are normally distributed within groups

2. Linearity: Scatter plots were used test for linearity

3. Multicollinearity: We run correlation test to test the strength and correlations among the dependent variables.

4. Homogeneity of variance-covariance matrix: Box's M Test was used to check the assumption of homogeneity of covariance matrices across the groups.

\section{Results}

The descriptive statistics of baby's weight over the factor levels are presented in Table 1 . The result revealed that the mean weights are not the same across all factor levels. For instance, in weight1 within feeding type, exclusive breast feeding (EBF) and complementary feeding (CF) had higher mean effect compared to breast milk substitute (BS). However, in weigh6, CF and BS had relatively higher mean effect than EBF. Meanwhile BS has higher standard deviation than $\mathrm{CF}$ and $\mathrm{EBF}$ in weight1. 
Table 1. Descriptive Statistics of Baby's Weight over the factors' levels.

\begin{tabular}{llll}
\hline Weight Gain & Feeding Type & Mean & Std Dev. \\
\hline Weight1 & EBF & 3.017 & 0.6293 \\
& CF & 3.062 & 0.6491 \\
Weight2 & BS & 2.762 & 0.7512 \\
& EBF & 4.421 & 0.8412 \\
& CF & 4.375 & 0.7566 \\
Weight3 & BS & 4.131 & 0.7901 \\
& EBF & 5.279 & 0.9283 \\
& CF & 5.267 & 0.8382 \\
Weight4 & BS & 5.146 & 0.7423 \\
& EBF & 6.098 & 0.9291 \\
& CF & 6.065 & 0.869 \\
Weight5 & BS & 5.785 & 0.7358 \\
& EBF & 6.714 & 0.8844 \\
Weight6 & FF & 6.793 & 0.9165 \\
& BS & 6.646 & 0.624 \\
& EBF & 7.181 & 0.8713 \\
Weight7 & CF & 7.322 & 1.0345 \\
& BS & 7.308 & 0.717 \\
& EBF & 7.71 & 0.9039 \\
& CF & 7.883 & 1.0251 \\
& BS & 7.738 & 0.7171 \\
\hline
\end{tabular}

The summary statistics of children weights over time grouped by gender is presented in Table 2 below. The minimum weights at the first month for males and females are $1.8 \mathrm{~kg}$ and $1.6 \mathrm{~kg}$ respectively with female babies recording the lower minimum weight compared to their counterpart. However, at the end of the seventh month period the female babies recorded the higher minimum weight than the male babies. The standard deviations for male and female children at month one was $0.6053 \mathrm{~kg}$ and $0.6995 \mathrm{~kg}$ respectively with the male babies recording the higher mean weight of $3.064 \mathrm{~kg}$ than their counterpart female of $2.961 \mathrm{~kg}$. Meanwhile the female children recorded a larger standard deviation compared to the male children. The results also revealed that the mean weight gain of children for the seven months period generally exhibited a nonlinear growth over time. This followed that the weight of a child does not essentially depend on the time the individual child was born.

Table 2. Descriptive Statistics of baby weight over time (in months) by sex.

\begin{tabular}{|c|c|c|c|c|c|c|c|c|}
\hline \multirow{2}{*}{ Time (months) } & \multicolumn{2}{|c|}{ Minimum } & \multicolumn{2}{|c|}{ Maximum } & \multicolumn{2}{|l|}{ Mean } & \multicolumn{2}{|c|}{ Sd. Deviation } \\
\hline & Male & Female & male & Female & Male & Female & Male & Female \\
\hline 1 & 1.8 & 1.6 & 4.5 & 4.9 & 3.064 & 2.961 & 0.6053 & 0.6995 \\
\hline 2 & 1.6 & 2.9 & 6.4 & 6.0 & 4.448 & 4.285 & 0.9189 & 0.6427 \\
\hline 3 & 3.0 & 3.4 & 7.6 & 6.8 & 5.343 & 5.176 & 0.9605 & 0.7433 \\
\hline 4 & 3.7 & 4.5 & 8.7 & 7.5 & 6.134 & 5.961 & 0.9649 & 0.7812 \\
\hline 5 & 4.5 & 5.0 & 8.8 & 8.0 & 6.857 & 6.644 & 0.9115 & 0.8263 \\
\hline 6 & 4.8 & 5.2 & 9.6 & 9.2 & 7.329 & 7.212 & 0.9682 & 0.9192 \\
\hline 7 & 5.2 & 5.6 & 10.0 & 9.7 & 7.895 & 7.717 & 0.9651 & 0.9317 \\
\hline
\end{tabular}

\subsection{Model Adequacy}

The Kolmogorov - Smirnov and Shapiro - Wilk's tests were used to test the assumption that the dependent variables are normally distributed within groups. The results of (Table 3) Kolmogorov-Smirnov and Shapiro-Wilk's clearly indicates that the populations were normally distributed since both tests have $p$ - values greater than 0.05 .

Table 3. Kolmogorov - Smirnov and Shapiro - Wilk's tests of Normality.

\begin{tabular}{llllll}
\hline & \multicolumn{2}{l}{ Kolmogorov-Smirnov } & & \multicolumn{2}{l}{ Shapiro-Wilk's } \\
\cline { 2 - 5 } & Statistic & Df & Sig. & Statistic & Df \\
\hline Weight 1 & 0.065 & 115 & 0.2000 & 0.983 & 115 \\
Weight 2 & 0.063 & 115 & 0.2000 & 0.983 & 0.166 \\
Weight 3 & 0.062 & 115 & 0.2000 & 0.991 & 0.143 \\
Weight 4 & 0.06 & 115 & 0.2000 & 0.994 & 0.619 \\
Weight 5 & 0.065 & 115 & 0.2000 & 0.991 & 115 \\
Weight 6 & 0.075 & 115 & 0.1590 & 0.988 & 115 \\
Weight 7 & 0.081 & 115 & 0.0600 & 0.989 & 0.645 \\
\hline
\end{tabular}

Table 4. Levene's Test of Equality of Error Variances.

\begin{tabular}{lllll}
\hline & F & Df 1 & Df 2 & Sig. \\
\hline Weight 1 & 1.063 & 1 & 113 & 0.305 \\
Weight 2 & 4.668 & 1 & 113 & 0.033 \\
Weight 3 & 2.154 & 1 & 113 & 0.145 \\
Weight 4 & 0.318 & 1 & 113 & 0.157 \\
Weight 5 & 0.000 & 1 & 113 & 0.998 \\
Weight 6 & 0.000 & 1 & 113 & 0.928 \\
Weight 7 & 0.283 & 1 & 113 & 0.596 \\
\hline
\end{tabular}

Further, the Levene's Test of equality of variance was insignificant $(P>0.05)$ implying that the variances are equal across the groups (Table 4). Also, Box's M Test of homogeneity of covariance matrices across the groups was highly insignificant (Box $M=50.371, F$-value $=1.68$, df1 = 28 , df $2=44237.233$ and $P$ value $=0.014)$, indicating that the covariance matrices of the dependent variables are equal across groups.

Also, Figure 1 present the scatter plots of the dependent variables. Clearly, the scatter plots revealed evidence of a positive correlation between the variables. The scatter plots do not show any evidence of nonlinearity, hence the assumption of linearity is satisfied. 

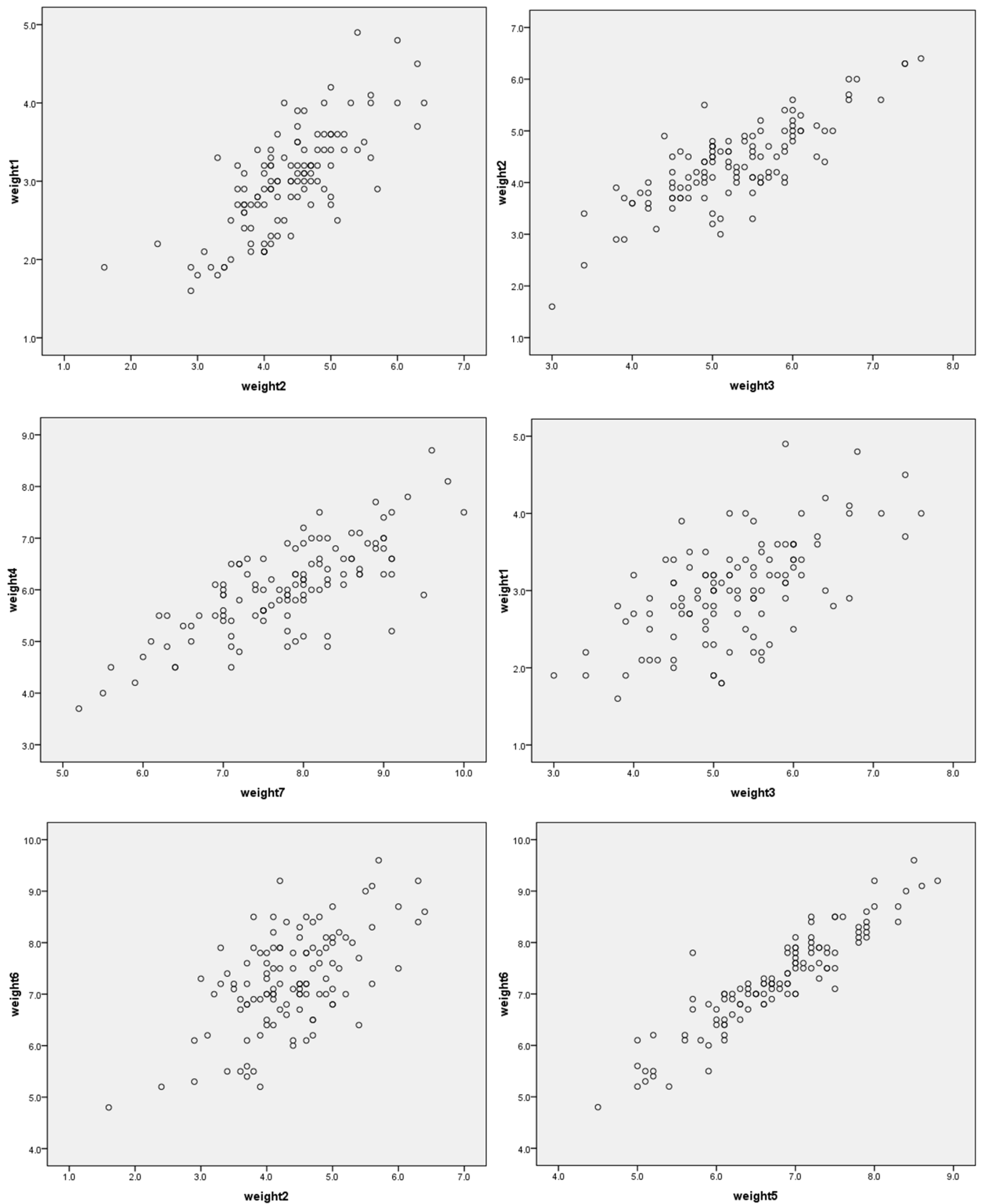

Figure 1. Scatter plots of Dependent Variables.

Further, a diagnostic test (Table 5) of multicollinearity by means of Pearson correlation test gave a $p$-value less than $1 \%$ level of significance, indicating that all the dependent variables are moderately correlated. The Pearson correlation appears to be positively high correlations. However, all the Pearson correlation values are below 0.9 except correlation between weight7 and weight 6 of (0.922) indicating that the variables are moderately correlated. 
Table 5. Pearson correlation for Dependent variables.

\begin{tabular}{|c|c|c|c|c|c|c|c|c|}
\hline \multicolumn{9}{|c|}{ Correlations } \\
\hline & & Weight 1 & Weight 2 & Weight 3 & Weight 4 & Weight 5 & Weight 6 & Weight 7 \\
\hline \multirow[t]{2}{*}{ Weight 1} & Pearson Correlation & 1 & 0.743 & 0.607 & 0.529 & 0.463 & 0.395 & 0.415 \\
\hline & Sig. (2-tailed) & & 0.000 & 0.000 & 0.000 & 0.000 & 0.000 & 0.000 \\
\hline \multirow[t]{2}{*}{ Weight 2} & Pearson Correlation & 0.743 & 1 & 0.798 & 0.724 & 0.633 & 0.583 & 0.579 \\
\hline & Sig. (2-tailed) & 0.000 & & 0.000 & 0.000 & 0.000 & 0.000 & 0.000 \\
\hline \multirow[t]{2}{*}{ Weight 3} & Pearson Correlation & 0.607 & 0.798 & 1 & 0.878 & 0.743 & 0.676 & 0.666 \\
\hline & Sig. (2-tailed) & 0.000 & 0.000 & & 0.000 & 0.000 & 0.000 & 0.000 \\
\hline \multirow[t]{2}{*}{ Weight 4} & Pearson Correlation & 0.529 & 0.724 & 0.878 & 1 & 0.85 & 0.766 & 0.756 \\
\hline & Sig. (2-tailed) & 0.000 & 0.000 & 0.000 & & 0.000 & 0.000 & 0.000 \\
\hline \multirow[t]{2}{*}{ Weight 5} & Pearson Correlation & 0.463 & 0.633 & 0.743 & 0.85 & 1 & 0.923 & 0.896 \\
\hline & Sig. (2-tailed) & 0.000 & 0.000 & 0.000 & 0.000 & & 0.000 & 0.000 \\
\hline \multirow[t]{2}{*}{ Weight 6} & Pearson Correlation & 0.395 & 0.583 & 0.676 & 0.766 & 0.923 & 1 & 0.922 \\
\hline & Sig. (2-tailed) & 0.000 & 0.000 & 0.000 & 0.000 & 0.000 & & 0.000 \\
\hline \multirow{2}{*}{ Weight 7} & Pearson Correlation & 0.415 & 0.579 & 0.666 & 0.756 & 0.896 & 0.922 & 1 \\
\hline & Sig. (2-tailed) & 0.000 & 0.000 & 0.000 & 0.000 & 0.000 & 0.000 & \\
\hline
\end{tabular}

Correlation is significant at the 0.01 level (2-tailed).

\subsection{Profile Analysis of Mean Weight of Babies}

The data for the study was first subjected to profile analysis in order visually compare the mean weight of babies across factor levels (see Figure 2). The profiles revealed that the mean change in baby's weights for both males and females over time followed the same patterns, indicating that the average change in weights of babies by gender may be the same or similar. However, average change in weights of babies for feeding type, change over time. Exclusive Breast Feeding (EBF) interacted with both Breast milk substitute (BS) and complementary Feeding (CF). This shows that feeding types may not be parallel. In other words, feeding type may have some effect on weights of babies.

Figure 2 further shows that the mean change in the weight of babies with respect to the mother's religious affiliation change over time and follows the same pattern. This may imply that the mean change in the weight of babies across maternal religion is similar. It is also observed that, the mean change in weights of babies over the seven-month period for maternal age group were changing over time and follows the same pattern. This implies that, the mean change in weight of babies maybe parallel irrespective of the maternal age group.

profile plot of weight against time

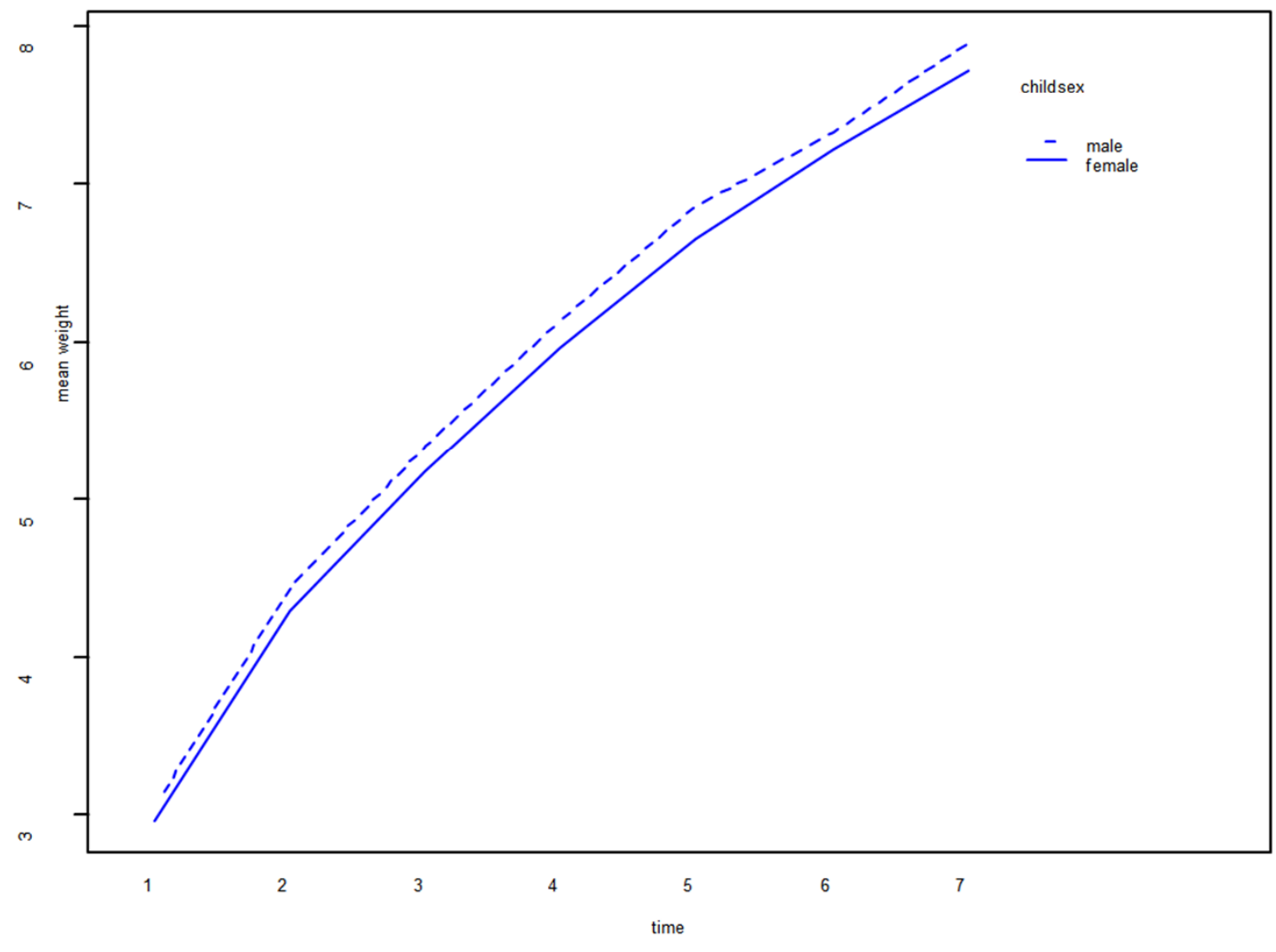



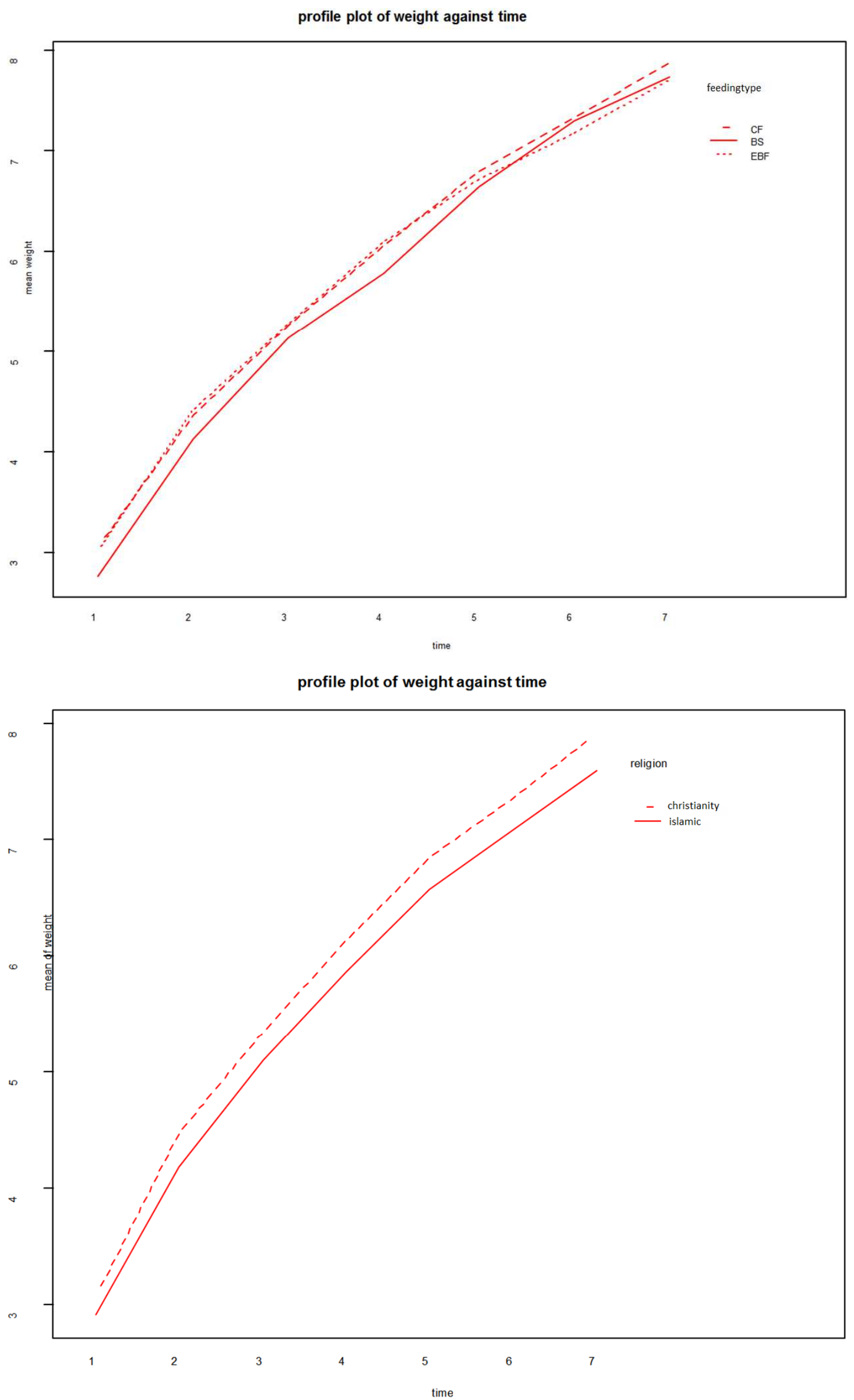




Figure 2. Profile Plot of Mean Weight of Babies by Baby's Gender, Feeding Type, Religion and Maternal Age Group.

\subsection{Main Effects Plots for Weights of Babies}

The main effects plot displays the means for each group within a categorical variable. When the line is horizontal, there is no main effect present, implying that the response mean is the same across all factor levels. However, when the line is not horizontal, there is a main effect present, indicating that the response mean is not the same across all factor levels. The steeper the slope of the line, the greater the magnitude of the main effect.

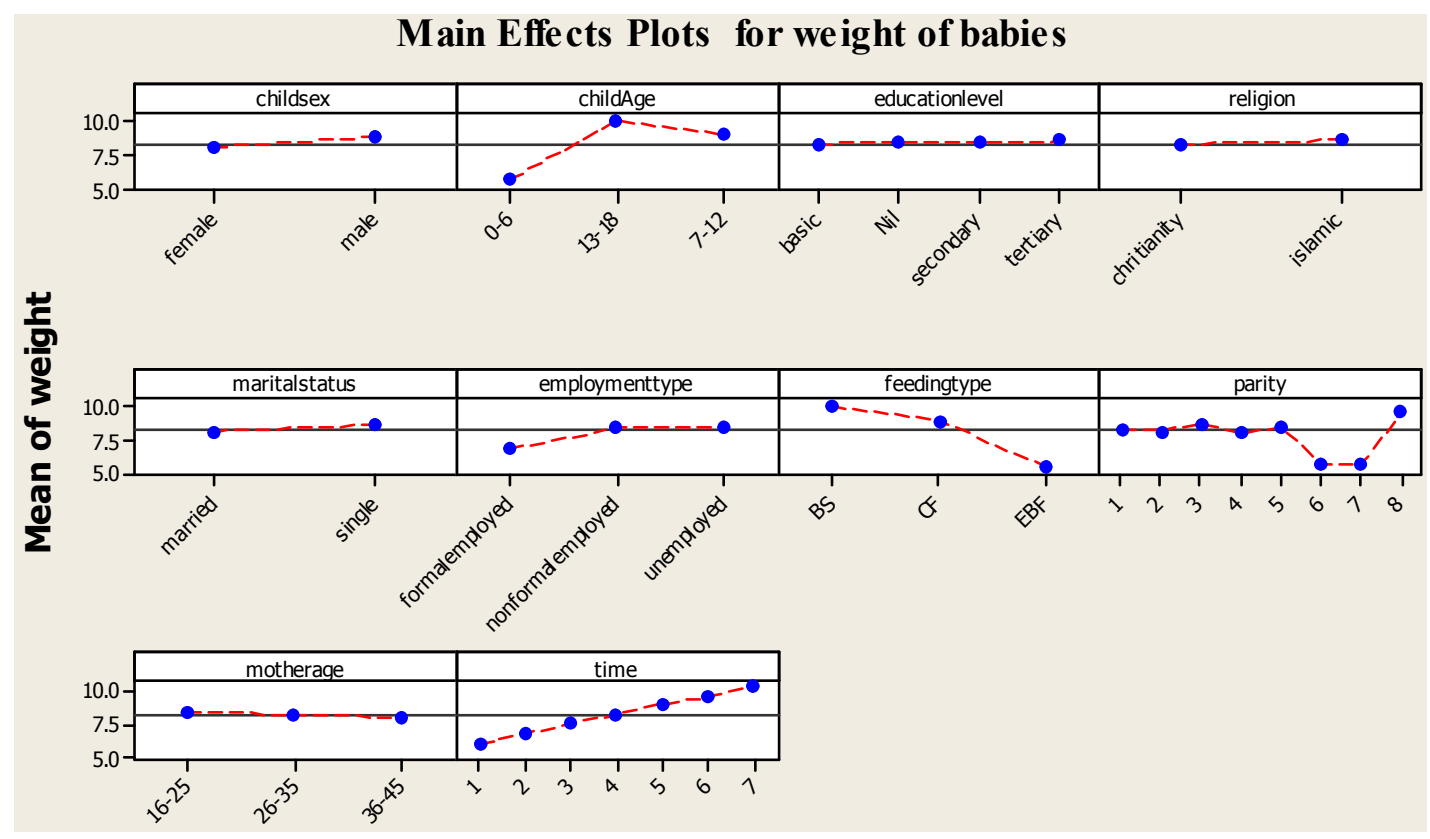

Figure 3. Main Effects Plot for Weights of Babies. 
From figure 3, it appears that baby's age group 0-6, Exclusive Breast Feeding (EBF), parity levels 6, 7 and mothers who were formally employed are associated with lower mean effects since they fall below the average mean weight. However, child age group 13-18, breast milk substitute and parity 7 are above the average mean weight line of 7.5, indicating that they are significant. Meanwhile, the response mean is the same across all the factor levels of child sex, mothers' educational level, religion, marital status and mothers' age, indicating that the mean weight of babies is the same across all their factors' levels.

\subsection{Interactions Plot}

Interaction plot compares the relative strength of the effects across factors. It is used to show how the relationship between one categorical factor and a continuous response, depends on the value of the second categorical factor. In interaction plot, parallel lines show no interaction whilst non parallel lines indicate that interaction occurs. The more non parallel the lines are, the greater the interaction.

The interactions plot shown in figure 4 revealed that the relationship between educational level, religion, marital status, feeding type and weight does not depend on the other predictors since their lines are parallel, thus no interaction. However, the relationship between parity, mother's age group, employment type and weight depend on other predictor variables. That is interaction occurs. For instance, parity depends on mother's age but mother's age does not depend on the child age group with respect to weight gain. Also, employment type neither depend on religion nor child age group but it depends on educational level with respect to weight gain.

\section{Interaction Plot (data means) for weight}

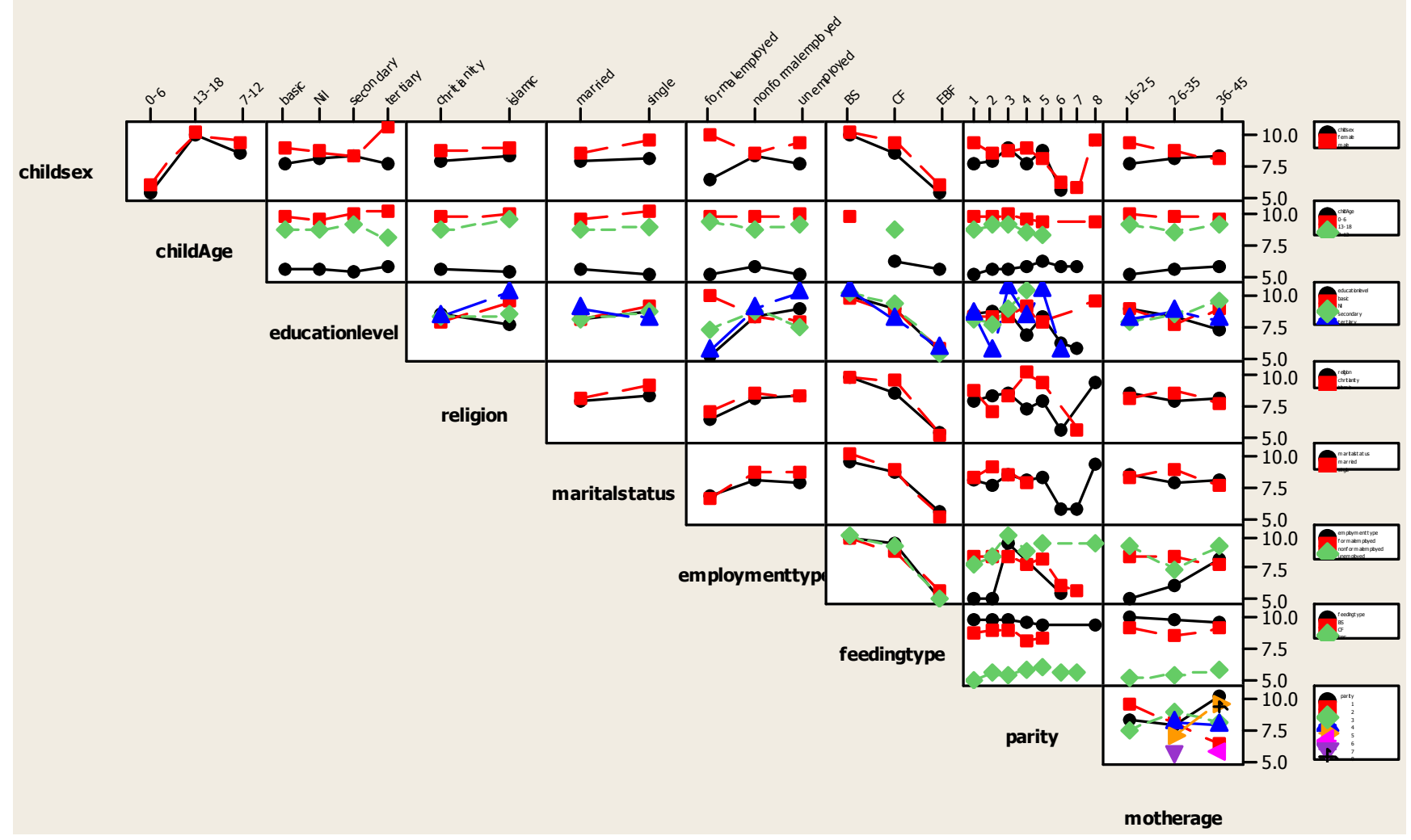

Figure 4. Interactions plot for weight of babies.

\subsection{Main Effects Test for Weights of Babies (MANOVA)}

In order to investigate the determinants of monthly mean weight gain, the MANOVA procedure was used. The results in Table 6 indicated that feeding type, parity and child age are the influential factors in determining weight gain of children less than five years, since there were significant at $5 \%$ level. This implies that feeding type given to children at their infant level and the baby's gender have significant impact on weight gain, and hence, are influential factors in determining the weight gain of children under five years whilst the other factors such as mother's age, marital status, mothers' religious affiliation etc. have no direct influence on weight gain of children less than five years. This agrees with Dinesh et al. assertion that deprivation of colostrum and improper complementary feeding were found to be significant risk factors for underweight among children less than five years [18]. 
Table 6. Multivariate Analysis of Weight Gain.

\begin{tabular}{|c|c|c|c|c|c|c|}
\hline Effect & Statistic & Value & F-Value & Hyp. Df & Error df & P-Value \\
\hline \multirow[t]{4}{*}{ Intercept } & Pillai's Trace & 0.975 & 350.389 & 7 & 62 & $0.000 *$ \\
\hline & Wilks' Lamda & 0.025 & 350.389 & 7 & 62 & $0.000 *$ \\
\hline & Hostelling's Trace & 39.56 & 350.389 & 7 & 62 & $0.000 *$ \\
\hline & Roy's Largest Root & 39.56 & 350.389 & 7 & 62 & $0.000 *$ \\
\hline \multirow[t]{4}{*}{ Child Sex } & Pillai's Trace & 0.1 & 0.98 & 7 & 62 & 0.454 \\
\hline & Wilks' Lamda & 0.9 & 0.98 & 7 & 62 & 0.454 \\
\hline & Hostelling's Trace & 0.111 & 0.98 & 7 & 62 & 0.454 \\
\hline & Roy's Largest Root & 0.111 & 0.98 & 7 & 62 & 0.454 \\
\hline \multirow[t]{4}{*}{ Mother's Educ. } & Pillai's Trace & 0.24 & 0.796 & 21 & 192 & 0.722 \\
\hline & Wilks' Lamda & 0.776 & 0.785 & 21 & 178.581 & 0.735 \\
\hline & Hostelling's Trace & 0.268 & 0.774 & 21 & 182 & 0.749 \\
\hline & Roy's Largest Root & 0.147 & 1.34 & 21 & 64 & 0.246 \\
\hline \multirow[t]{4}{*}{ Marital Status } & Pillai's Trace & 0.24 & 0.219 & 7 & 62 & 0.98 \\
\hline & Wilks' Lamda & 0.976 & 0.219 & 7 & 62 & 0.98 \\
\hline & Hostelling's Trace & 0.025 & 0.219 & 7 & 62 & 0.98 \\
\hline & Roy's Largest Root & 0.025 & 0.219 & 7 & 62 & 0.98 \\
\hline \multirow[t]{4}{*}{ Feeding Type } & Pillai's Trace & 1.252 & 24.864 & 14 & 208 & $0.000^{*}$ \\
\hline & Wilks' Lamda & 0.56 & 47.427 & 14 & 208 & $0.000 *$ \\
\hline & Hostelling's Trace & 11.342 & 82.635 & 14 & 208 & $0.000 *$ \\
\hline & Roy's Largest Root & 10.835 & 160.979 & 14 & 104 & $0.000 *$ \\
\hline \multirow[t]{4}{*}{ Occupation } & Pillai's Trace & 0.185 & 0.919 & 14 & 126 & 0.541 \\
\hline & Wilks' Lamda & 0.822 & 0.913 & 14 & 124 & 0.547 \\
\hline & Hostelling's Trace & 0.208 & 0.906 & 14 & 122 & 0.554 \\
\hline & Roy's Largest Root & 0.15 & 1.349 & 14 & 63 & 0.243 \\
\hline \multirow[t]{4}{*}{ Mother's Age } & Pillai's Trace & 0.079 & 0.442 & 14 & 150 & 0.958 \\
\hline & Wilks' Lamda & 0.922 & 0.439 & 14 & 148 & 0.959 \\
\hline & Hostelling's Trace & 0.084 & 0.437 & 14 & 146 & 0.96 \\
\hline & Roy's Largest Root & 0.068 & 0.729 & 7 & 75 & 0.648 \\
\hline \multirow[t]{4}{*}{ Parity } & Pillai's Trace & 0.496 & 0.871 & 49 & 560 & 0.72 \\
\hline & Wilks' Lamda & 0.575 & 0.893 & 49 & 148 & 0.678 \\
\hline & Hostelling's Trace & 0.623 & 0.92 & 49 & 506 & 0.63 \\
\hline & Roy's Largest Root & 0.392 & 4.48 & 7 & 80 & $0.000 *$ \\
\hline \multirow[t]{4}{*}{ Religion } & Pillai's Trace & 0.048 & 0.446 & 7 & 62 & 0.869 \\
\hline & Wilks' Lamda & 0.952 & 0.446 & 7 & 62 & 0.869 \\
\hline & Hostelling's Trace & 0.05 & 0.446 & 7 & 62 & 0.869 \\
\hline & Roy's Largest Root & 0.05 & 0.446 & 7 & 62 & 0.869 \\
\hline \multirow[t]{4}{*}{ Child Age } & Pillai's Trace & 0.933 & 198.302 & 7 & 100 & $0.000 *$ \\
\hline & Wilks' Lamda & 0.067 & 198.302 & 7 & 100 & $0.000 *$ \\
\hline & Hostelling's Trace & 13.881 & 198.302 & 7 & 100 & $0.000 *$ \\
\hline & Roy's Largest Root & 13.881 & 198.302 & 7 & 100 & $0.000 *$ \\
\hline
\end{tabular}

$*$.= Significant at $5 \%$

Furthermore, to test whether there were interactions among the factors on monthly mean weight gain, the MANOVA procedure was once again used. The results (Table 7) revealed that there exists a statistically significant interaction effect, between mothers' education and feeding type, mother's age and between occupation and mother's age group and parity on the combined dependent variables (weight gain). This implies that there are relationship between parity and mother's age group, occupation type and maternal age group and between mothers' education and feeding type on weight gain of children less than five years. However, test of significance of the other parameters of the model revealed that there were no significant interactions between them at $5 \%$ level of significance.

Table 7. Results of MANOVA for Interactions.

\begin{tabular}{|c|c|c|c|c|}
\hline Effect & Statistic & Value & F Value & P-Value \\
\hline \multirow[t]{3}{*}{ ChildSex*FeedingType } & Pillai's Trace & 0.047 & 0.36 & 0.984 \\
\hline & Wilks' Lamda & 0.953 & 0.358 & 0.984 \\
\hline & Hostelling's Trace & 0.049 & 0.356 & 0.985 \\
\hline \multirow[t]{3}{*}{ Childsex*mothersedu } & Pillai's Trace & 0.133 & 0.68 & 0.852 \\
\hline & Wilks' Lamda & 0.872 & 0.674 & 0.857 \\
\hline & Hostelling's Trace & 0.141 & 0.669 & 0.863 \\
\hline \multirow[t]{3}{*}{ Mothersedu*feedingtype } & Pillai's Trace & 0.433 & 1.135 & 0.263 \\
\hline & Wilks' Lamda & 0.627 & 1.144 & 0.254 \\
\hline & Hostelling's Trace & 0.506 & 1.148 & 0.246 \\
\hline
\end{tabular}




\begin{tabular}{lllll}
\hline Effect & Statistic & Value & F Value & P-Value \\
\hline \multirow{3}{*}{ occupation*mothersage } & Roy's Largest Root & 0.242 & 3.526 & $0.002^{*}$ \\
& Pillai's Trace & 0.334 & 1.343 & 0.117 \\
& Wilks' Lamda & 0.7 & 1.342 & 0.119 \\
& Hostelling's Trace & 0.38 & 1.336 & 0.121 \\
Mothersage*parity & Roy's Largest Root & 0.188 & 2.76 & $0.011^{*}$ \\
& Pillai's Trace & 0.313 & 0.762 & 0.863 \\
& Wilks' Lamda & 0.718 & 0.756 & 0.867 \\
Maritalstatus*childage & Hostelling's Trace & 0.351 & 0.754 & 0.871 \\
& Roy's Largest Root & 0.187 & $0.017^{*}$ \\
& Pillai's Trace & 0.148 & 0.284 \\
& Wilks' Lamda & 0.856 & 1.19 & 0.288 \\
& Hostelling's Trace & 0.162 & 1.182 & 0.291 \\
\hline
\end{tabular}

$*=$ Significant at $5 \%$

The Multivariate analysis of variance results confirm the profile plots. Since factors such as mother's occupation, child's sex, religion, marital status and mother's age were not significant in the MANOVA results hence, require test of parallelism equality and flatness.

The results of Table 8 indicated that both tests of parallelism and equality were not significant ( $\mathrm{p}$ - values $>0.05$ ). Hence, we fail to reject the hypothesis of same profiles and conclude that the change in weights of babies were parallel and equal for both test of parallelism and equality. However, the test of flatness revealed that the four multivariate tests had $p$-values $<0.05$ and thus we reject the hypothesis that the profiles are the same.

Table 8. Test of Parallelism, equality and flatness by mother's education.

\begin{tabular}{|c|c|c|c|c|c|}
\hline \multicolumn{6}{|l|}{ Test of Parallelism } \\
\hline Variable & & Value & F - Value & & Sig. \\
\hline \multirow[t]{4}{*}{ Mother's Education } & Pillai's Trace & 0.118 & 0.740 & & 0.769 \\
\hline & Wilks' Lamda & 0.885 & 0.733 & & 0.776 \\
\hline & Hotelling's Trace & 0.125 & 0.727 & & 0.783 \\
\hline & Roy's Largest Root & 0.071 & 1.277 & & 0.274 \\
\hline \multicolumn{6}{|l|}{ Test of Equality } \\
\hline Source & Type 111 Sum of Square & Df & Mean Square & F - Value & Sig. \\
\hline Intercept & 21077.941 & 1 & 21077.941 & 5542.1177 & $0.000 *$ \\
\hline Mother's Education & 8.127 & 3 & 2.709 & 0.7120 & 0.547 \\
\hline Error & 422.158 & 111 & 3.803 & & \\
\hline \multicolumn{6}{|l|}{ Test of Flatnesss } \\
\hline & & Value & F - Value & & Sig. \\
\hline \multirow[t]{4}{*}{ Mother's Education } & Pillai's Trace & 0.959 & 413.01 & & $0.000^{*}$ \\
\hline & Wilks' Lamda & 0.041 & 413.01 & & $0.000^{*}$ \\
\hline & Hotelling's Trace & 23.378 & 413.01 & & $0.000 *$ \\
\hline & Roy's Largest Root & 23.378 & 413.01 & & $0.000 *$ \\
\hline
\end{tabular}

*=Significant at $0.05 \%$

Table 9 presents the test of parallelism, equality and flatness which revealed that there no significant difference $(P$-values $>0.05)$ and hence we fail to reject the hypothesis of the same profiles and conclude that the mean change in weights of babies did not differ by mother's age group over time. Hence, the test of flatness was carried out. The result of the flatness tests revealed that all the multivariate tests were significant, with $\mathrm{p}$ - values $<0.05$.

Table 9. Test of parallelism, Equality and Flatness by Maternal Age Group.

\begin{tabular}{|c|c|c|c|c|c|}
\hline \multicolumn{6}{|l|}{ Test of Parallelism } \\
\hline Variable & & Value & F - Value & & Sig. \\
\hline \multirow[t]{4}{*}{ Mother's Education } & Pillai's Trace & 0.118 & 0.740 & & 0.769 \\
\hline & Wilks' Lamda & 0.885 & 0.733 & & 0.776 \\
\hline & Hotelling's Trace & 0.125 & 0.727 & & 0.783 \\
\hline & Roy's Largest Root & 0.071 & 1.277 & & 0.274 \\
\hline \multicolumn{6}{|l|}{ Test of Equality } \\
\hline Source & Type III Sum of Square & Df & Mean Square & F - Value & Sig. \\
\hline Intercept & 21077.941 & 1 & 21077.941 & 5542.1177 & $0.000^{*}$ \\
\hline Mother's Education & 8.127 & 3 & 2.709 & 0.7120 & 0.547 \\
\hline Error & 422.158 & 111 & 3.803 & & \\
\hline
\end{tabular}




\begin{tabular}{|c|c|c|c|c|}
\hline \multicolumn{5}{|l|}{ Test of Flatness } \\
\hline & & Value & F - Value & Sig. \\
\hline \multirow[t]{4}{*}{ Mother's Education } & Pillai's Trace & 0.959 & 413.01 & $0.000 *$ \\
\hline & Wilks' Lamda & 0.041 & 413.01 & $0.000 *$ \\
\hline & Hotelling's Trace & 23.378 & 413.01 & 0.000 * \\
\hline & Roy's Largest Root & 23.378 & 413.01 & $0.000 *$ \\
\hline
\end{tabular}

*. Significant at $5 \%$

\section{Discussion}

The records of one hundred and fifteen (115) weights of babies from the Kaintampo Reproductive and Child Health $(\mathrm{RCH})$ weighing center, the only weighing center that serve the whole Kintampo town in the Kintampo municipality were retrospectively monitored from June, 2014 to March, 2016. Out of the one hundred and fifteen babies, 56 were males whilst 59 were females. The result revealed that the mean weights gain of children depends on feeding type (exclusive breast feeding (EBF), complementary feeding (CF) and breast milk substitute (BS)).

The minimum weights at the first month for males and females are $1.8 \mathrm{~kg}$ and $1.6 \mathrm{~kg}$ respectively with female babies recording the lower minimum weight compared to their counterpart. However, at the end of the seventh month period the female babies recorded the higher minimum weight than the male babies.

The parallelism and equality tests were statistically insignificant, indicating that the pattern of growth for both male and female babies are the same and identical with the mean weight gain over time. The parallelism and equality tests for mother's age group was not statistically significant $(\mathrm{P}>0.05)$. This indicated that the profiles of average weights gain for the different age group are approximately the same. The flatness test however, was significant, meaning the mean weight gain with respect to mother's age does not remain the same overtime. Also, parallelism and equality tests for mother's educational level showed no significant effect $(\mathrm{P}>0.05)$, indicating that the mean weights gain of babies follows the same pattern by mother's educational level for both parallel and equal profile tests. A subsequent test for flatness showed that all the four multivariate tests were significant ( $p$-values $<0.05)$. Hence, the reject the hypothesis of same profiles and conclude that the pattern of change in the weights of babies were not constant (not flat) with respect to mother's education overtime. This may implied that older mothers are more experience in taking good care of their children than their younger counterparts.

The MANOVA results revealed that feeding type, parity and child age are the influential factors in determining the weight gain of children less than five years, since there were significant at 5\% level. This result is consistent with Maahi and Haadi, and Küpers et al. whose findings revealed that age, Birth weight and feeding practice are the most influential factors for determining children weight gain ([13], [19]). It however, disagrees with Akansuke et al. assertion that breast feeding type was not significantly different at $5 \%$ significant level for average weight change and De Jesus et al. that primiparity and maternal employment outside the home were associated with overweight in children ([20], [21]). The other factors such mothers education, marital status, occupation religion and mothers age were not significant in determining children under five years weight gain.

The study further revealed that, there exists some relationship between feeding type and mother's education, parity and mother's age group and between occupation and mother's age group with respect to weight gain. Thus, their interactions were significant, $(\mathrm{P}<0.05)$, as shown in Table 6 . This suggests that the feeding type given to children in terms of weight gain depends on the mother's educational level thus confirming the results of the profile analysis. Therefore, we may conclude that high educated mothers are able to feed well and take good care of their children than low educated mothers, perhaps, because they are able to understand better and adhere to maternal and child health care educations offered by the midwives and other service providers.

Moreover, the parity group of the children on weight gain depends on the maternal age. This may also suggest that mothers who fall within higher age group are able to give birth many children than mothers who fall within lower age group. However, there were no relationships between the other categorical factors such as child's sex and feeding type, child's sex and educational level of the mother and between marital status and child s age, $(\mathrm{P}$-values $>0.05)$, in relation to weight gain.

\section{Conclusions and Recommendations}

In this study, the determinants of weight gain by children under-five years in the Kintampo municipality of the Bono East Region of Ghana were investigated. The result showed that the mean weights gain of children depends on feeding type (exclusive breast feeding (EBF), complementary feeding (CF) and breast milk substitute (BS)).

The results revealed that feeding type, parity and child age were useful in explaining weight gain of children less than five years. The study revealed that there exist some relationship between feeding type and mother's education, parity and mother's age group and between occupation and mother's age group with respect to weight gain. However, the studies revealed that the pattern of weight gain by babies were not constant with respect to mother's education and mother's age group overtime. It is therefore recommended that medical experts should continue encouraging nursing mothers to feed their children themselves and pay regular 
visits to weighing center and seek child health care to avoid complications during the infant stage.

\section{References}

[1] UNICEF (2013) The state of the world's children. New York, USA: UNICEF.

[2] Isiugo-Abanihe, U. C. and Oke, O. A. (2011) Maternal and environmental factors influencing infant birth weight in Ibadan, Nigeria. African Popul Stu, 25 (2): 250-66.

[3] Leppert, P. C., Namerow, P. B. and Barker, (1986) D. Pregnancy outcomes among adolescent and older women receiving comprehensive prenatal care. J Adolesc Health Care 7 (2): 112-133

[4] Abel, E. L., Kruger, M. and Burd, L. (2002) Effects of maternal and paternal age on Caucasian and Native American preterm births and birth weights. Am J Perinatol, 19 (1), 4954.

[5] Dhall, K., \& Bagga. R. (1995). Maternal determinants of birth weight of North Indian babies. The Journal of Pediatrics volume, 62 (3), 333-344.

[6] Parker, J. D. and Schoendorf, K. C. (1994) Influence of Paternal Characteristics on the Risk of Low Birth Weight." American Journal of Epidemiology, 136 (4): 399-407.

[7] Deshmukh, J. S., Motghare, D. D., Zodpey, S. P. and Wadhva, S. K. (1998) Low birth weight and associated maternal factors in an urban area. Indian Pediatrics, 35 (1); 33-36.

[8] Tuntiseranee, P., Olsen, J., Chongsuvivatwong, V. and Limbutara, S. (1999) Socio-economic and work-related determinants of pregnancy outcome in southern Thailand. $J$. Epidemiol Community Health. 53 (10): 624-9.

[9] Langhoff-Roos, J., Lindmark, G., Gustavson, K. H., GebreMedhin, M. and Meirik, O. (1987). Relative effect of parental birth weight on infant birth weight at term. Clinical Genetics, $32,240-248$.

[10] Mavalankar, D. V., Trivedi, C. C. and Gray, R. H. (1994) Maternal weight, height and risk of poor pregnancy outcome in Ahmedabad, India. Indian Pediatrics, 31 (10), 1205-1212.

[11] Claris O, Beltrand J, Levy-Marchal C (2010). Consequences of intrauterine growth and early neonatal catch-up growth. 34 : 207-10.

[12] Monteiro P. O. and Victora C. G. (2005). Rapid growth in infancy and childhood and obesity in later life - a systematic review. PMID. 6: 143-154.

[13] Maahi T, Haadi A (2014). Analysis of Repeated Measures of Weight of Children under Five Years, A Comparative Analysis between Male and Female Children (CASE STUDY: Tamale Metropolis. International Journal of Sciences. 3 (5).

[14] Black, R. E., Allen L. H. Bhutta Z. A., Caulfield L. E., De Onis M., Ezzati M., Mathers C. and Rivera J. (2008). Maternal and child undernutrition: global and regional exposures and health consequences. PMID: 18207566 DOI: 10.1016/S01406736(07)61690-0.

[15] Bocca G, Corpeleijn E, van den Heuvel ER, Stolk RP, Sauer PJ (2014). Three-year follow-up of 3-year-old to 5-year-old children after participation in a multidisciplinary or a usualcare obesity treatment program. PMID. 33: 1095-1100.

[16] Danielsson P, Kowalski J, Ekblom O, Marcus C. (2012). Response of severely obese children and adolescents to behavioral treatment. 166: 1103-8.

[17] Johnson R. A., Wichern D. W. (2007). Applied multivariate statistical analysis, 6th ed. Prentice Hall, Upper Saddle River.

[18] Dinesh K, Goel N. K., Poonam C. (2006). Influence of InfantFeeding Practice on Nutritional Status of Under-Five Children. Department of Community Medicine, GMCH, Sector 32a, Chandigarh, India. Indian Journal of Pediatrics 73 (5), 417-421.

[19] Küpers L K, L'Abée C, Bocca G, Stolk R. P., Sauer P. J. J., Corpeleijnb E. (2015). Determinants of Weight Gain during the First Two Years of Life-The GECKO Drenthe Birth $\begin{array}{lllll}\text { Cohort. PLoS ONE } 10 & \text { (7): e0133326. doi: }\end{array}$ 10.1371/journal.pone.0133326.

[20] Akansuke M. A., Luguterah A., Nyandanu S. D., Nawumbeni D. N., Adampa T. (2015). Profiling the determinants of baby weights in Bolgatanga Municipality of Ghana. Journal of Biology and Life Science, 6 (2), 1-23.

[21] De Jesus G. M., Vieira G. O., Vieira T. O., Martins C. C., Mendes C. M., Castelão E. S. (2010). Determinants of overweight in children under 4 years of age. J Pediatr (Rio J). 86 (4): 311-316. 